\title{
Specialized project in biophotonics
}

Agueda Garcia Martin, Pedro Sastriques-Silva, Julia Martinez-Fundora, Angel Augier Calderin, Xonia LopezCepero

Agueda L. Garcia Martin, Pedro O. Sastriques-Silva, Julia Nancy MartinezFundora, Angel G. Augier Calderin, Xonia Lopez-Cepero, "Specialized project in biophotonics," Proc. SPIE 3831, Sixth International Conference on Education and Training in Optics and Photonics, (16 June 2000); doi: $10.1117 / 12.388719$

Event: Education and Training in Optics and Photonics (ETOP'99), 1999, Cancun, Mexico 


\title{
SPECIALIZED PROJECT IN BIOPHOTONICS
}

\author{
Agueda L. Garcia Martin ${ }^{\bullet a}$, Pedro O. Sastriques Silva ${ }^{\text {b }}$, \\ Julia Nancy Martinez Fundora ${ }^{c}$, Angel Augier Calderin ${ }^{a}$, Xonia Lopez Cepero ${ }^{b}$ \\ a Higher Polytechnic Institute “Jose Antonio Echeverria”, CP 6028, Havana, Cuba \\ ${ }^{b}$ Psychiatry Hospital of Havana, Havana, Cuba \\ ${ }^{c}$ Health Interdisciplinary Communitary Complex, Havana, Cuba
}

\begin{abstract}
As science advances, it is more evident the necessity of a health interdisciplinary approach in Medicine. In the case of medical applications of light, the knowledge of the use of dispositives, equipment, diagnostic and treatment means, as well as the bases for the use of this update technologies is required. At the present moment, the outstanding work of specialized professionals of different profiles requires personnel with high professional formation in keeping with the latest trends in science and technology. The authors present here an Specialized Project in Biophotonics, with the aim of increasing the professional preparation of university graduates with an ample profile - physicists and engineers - who work in Biomedical Optics, thus contributing to the specialized formation of medic and paramedic personnel. The course is structured into sixsubject-modules and into two phases. As to the basic professional formation, each one attending this course, will select between two variants of the Basic Formation Postgraduate Course: Anatomy and Physiology, Physical Bioenergetics, Clinic Bioenergetics; or Physics in Medicine, Optics and Applied Information Theory, depending on the student's professional profile. In the second phase, the General Formation Postgraduate Course: Biomedical Optics, Optical Bioenergetics and Laser in Medicine.
\end{abstract}

Keywords: Postgraduate Education, Life Sciences, Biomedical Optics, Training in Optics, Biophotonics.

\section{INTRODUCTION}

The interest on light, its nature and its applications, has been present in all the periods of human development. Philosophers, physicists ${ }^{1-3}$, physicians, engineers, artists, psychologists, etc, have all meditated about the nature of light. As to their professional interests, they have applied light in diverse objectives and they have interpreted the use of light in different ways.

The interaction of light with living beings has been a useful and fascinating issue, and it is still so in Science and Technology. In the case of man, the processes of interaction condition a set of applications in diagnosis as well as therapeutics.

The luminous therapies or optic therapies have ancient origins. In the occidental world, in Ancient Greece, to be more precise, Heliotherapy emerged as a therapeutic practice. This technique used light coming from the sun, but in the oriental world, for a longer period of time, colors were already used. The colors were associated to the "chakras" (in Indian Ayurvedic Medicine) and these were associated to the exogenic causes of sicknesses and to the different types of energy (in Chinese Medicine) too. These are known today as Cromotherapy or Colortherapy.

In the occidental world the development of luminous therapies has been conditioned to the technological development and to the construction of new artificial luminous sources. The first investigations began in Europe at the end of the nineteenth century, so much on animals as on human beings. In this way, Phototherapy emerged, so by the beginnings of the twentieth century, it gave way to a successful utilization of red, blue, and violet lights on different disturbances. In the first decade of the twentieth century, Chemotherapy emerged and the aforementioned luminous technique was forgotten. The infrared lamp

- Correspondence: Email: aguedag@electrica.ispjae.edu.cu, Telephone: (537) 295785, Fax: (537) 271574 
for its beneficial thermal effects and the ultra-violet lamp for its successful application on skin affections were the only survivors.

By the middle of the twentieth century, the appearance of laser opened new horizons in biomedical applications of light. Methods and biomedical technologies developed quickly for diagnostic and therapeutic aims.

Nevertheless, in relation to luminous therapies, the mechanisms for the action of light on the human body are not very well known. These mechanisms, although not always accepted, give bases to today's well-known clinical effects.

Laser therapies and the luminous ones in general, have an avant-garde interest on medic-biological professional profile. This issue is debated as to science and the impetuous development of modern technology. As to diagnosis, light is the basis of a varied equipping already in the market. Light is also the basis of new investigations and new results that are introduced gradually into medical practice. In general, the possibilities of its not invasive action, give light, a promising future.

During the last years, Bioenergetics Medicine ${ }^{4,5}$ has emerged with a growing popularity. It is based on the best results of Traditional Medicine and the great amount of scientific and technological information of Occidental Medicine, although it has its own system of concepts and theories. Bioenergetics Medicine also uses light with therapeutic and diagnostic purposes.

For all the above mentioned, the interest of specialists of a medic-biologic profile, is growing constantly. At the present moment, light has a special interest as to the scientific and technological order in the Life Sciences and Biomedical Technologies as well. In reference to luminous therapies, for example, although they are known in Medicine, the use of light has met with difficulties and still does. This interdisciplinary treatment makes it a necessity at present.

It is necessary to deepen on the effects of light and to increase on the quality of investigation that offers greater information about its mechanisms. Only through this interdisciplinary treatment it would be possible to integrate, in a coherent way, the promising perspectives of the use of light as to health benefits and to increase the quality of life.

The necessity to approach this field of knowledge with an interdisciplinary treatment, justifies the offering of an academic post-graduate project, which may convey to the interests already mentioned. This is our hearty inspiration and motivation of this Specialized Project in Biophotonics.

\section{SPECIALIZED PROJECT IN BIOPHOTONICS}

\subsection{Professional Profile}

Specialized Project in Biophotonics addresed to:

- Professionals of medic-biological profile as physicians, biologists, and biochemists, who have become involved in biomedical applications based on light.

- Physicists and engineers that research in the medic-biological applications of light.

- Professionals that work in areas of investigation related to the development of biomedical technologies based on light.

- Professionals of biomedical equipment.

- Members of interdisciplinary biomedical research groups.

\subsection{Objectives}

\subsubsection{General Objectives}

- To increase the professional preparation as to knowledge and abilities of an ample-profile university graduate as in the case of physicists and engineers that work in Biomedical Optics.

- To contribute to the specialized formation of the medical and paramedic personnel that seeks to guide, apply, or investigate on the application of light with therapeutic and diagnostic purposes with a high level of professionalism.

- To form specialists able to assimilate, develop and enlarge the applications of light in Medicine and Biology as well as to introduce methods, equipment and systems based on this physical process. 


\subsubsection{Specific Objectives}

- To contribute to the formation of the medical and paramedic personnel that use biomedical technologies based on light.

- To contribute to research in the interaction of light on living beings.

- To appropriately apply methods, techniques, and biomedical instruments that use light.

- To know and to explain the biological, physiologic and clinical effects of light to apply luminous therapies.

- To develop fundamental and clinical investigations in this field of knowledge.

- To introduce new applications of light in Medicine and Biology.

\section{STRUCTURE OF SPECIALIZED PROJECT IN BIOPHOTONICS}

This Project intends to form specialists capable of assimilating, and developing the application of light in Medicine and Biology. In this way, the present SPECIALIZED PROJECT IN BIOPHOTONICS will introduce new scientific ways of working with update equipment, techniques and high technology systems based on this physical process.

The Specialized Project in Biophotonics is structured into six-subject-modules and into two phases.

Keeping in mind the diversity of professional profiles of the university graduate to whom these project is addressed, this specialized course is conceived into two well-differentiated phases, each one based on three module-course. See Fig. 1.

- Basic Formation Phase

- Specialized Formation Phase

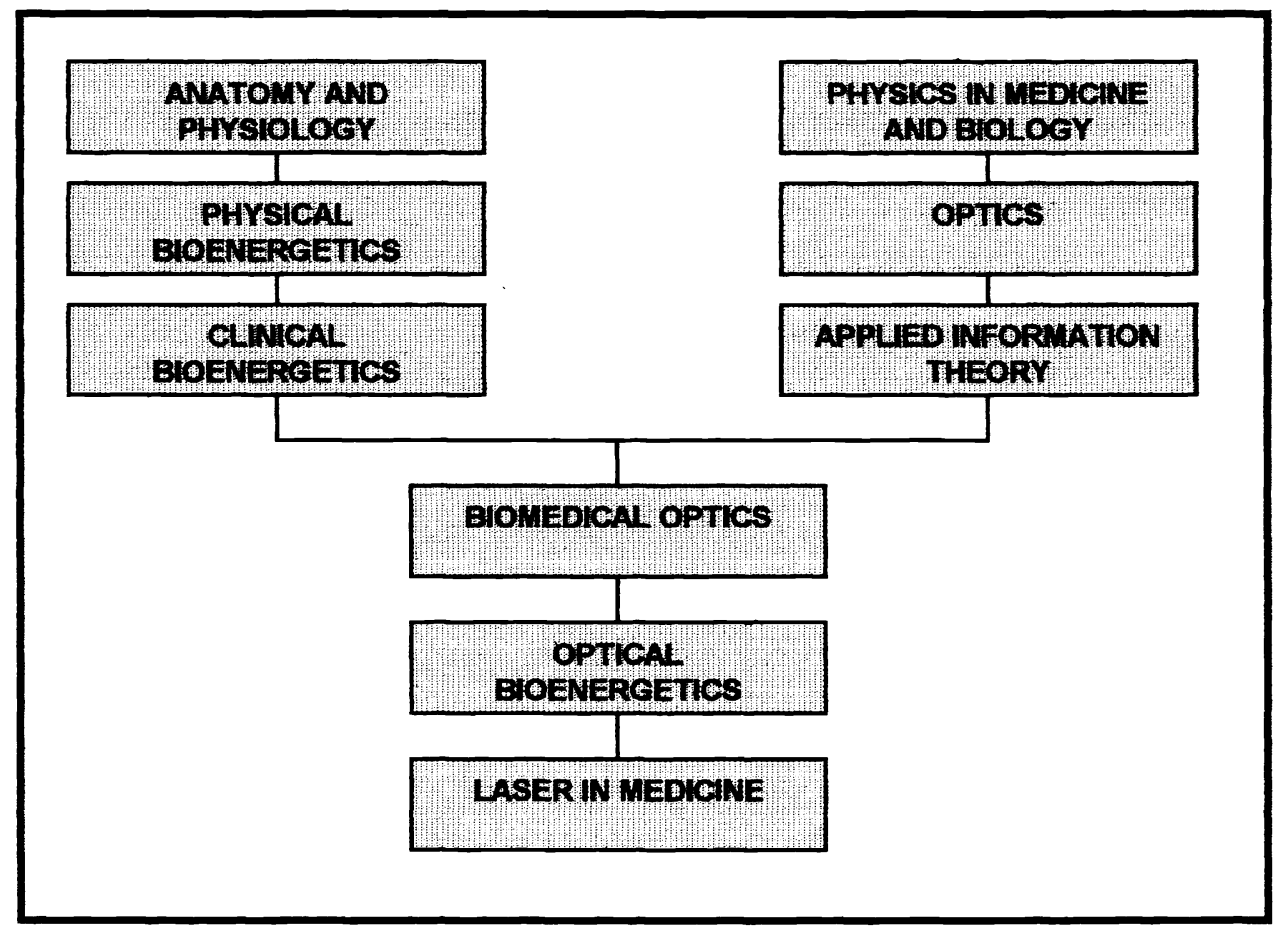

Figure 1. These subjects are mentioned in the chart. 


\subsection{Basic Formation Phase}

As to the basic professional formation, each one attending this course will select between two variants of the Basic Formation Phase. The two options are conceived depending on the student's professional profile.

Option A: For students who have a physical or technical formation, the subjects are: Anatomy and Physiology, Physical Bioenergetics, and Clinical Bioenergetics.

Option B: For the students who have a medic-biological formation, the subjects are: Physics in Medicine, Optics, and Applied Information Theory.

\begin{tabular}{|c|c|c|c|}
\hline \multicolumn{2}{|c|}{ Option A } & \multicolumn{2}{c|}{ Option B } \\
\hline Subject & Duration & Subject & Duration \\
\hline Physiology and Anatomy & $\mathbf{4 5}$ hours & $\begin{array}{c}\text { Physics in Medicine } \\
\text { And Biology }\end{array}$ & $\mathbf{4 5}$ hours \\
\hline Physical Bioenergetics & $\mathbf{3 0}$ hours & Optics & 30 hours \\
\hline Clinical Bioenergetics & $\mathbf{3 0}$ hours & Applied Information Theory & 30 hours \\
\hline
\end{tabular}

\subsection{Specialized Formation Phase}

The three remaining modules will be common to all students. In this second phase, the General Formation Postgraduate Course has the following subjects: Biomedical Optics, Optical Bioenergetics, and Laser in Medicine.

\begin{tabular}{|c|c|}
\hline Subject & Duration \\
\hline Biomedical Optics & 45 hours \\
\hline Optical Bioenergetics & 45 hours \\
\hline Laser in Medicine & 30 hours \\
\hline
\end{tabular}

\section{CONTENTS}

\subsection{Basic Formation Phase}

\subsubsection{Option A}

\section{ANATOMY AND PHYSIOLOGY - (45 hours)}

\section{General objectives}

- To describe the anatomy and physiology of the human body.

\section{Specific objectives}

- To explain the mechanisms involved in the cellular membrane.

- To describe the mechanism in which occur the transmission of potential action of the cell.

- To characterize the functional principles of the human body and its physiological bases. 


\section{PHYSICAL BIOENERGETICS - (30 hours)}

\section{General objective}

- To explain the system of concepts and theories that are the base of bioenergetic aspects focusing on the human being.

\section{Specific objectives}

- To characterize the several types of bodies and the relationship between them.

- To describe the elements or components of the global Polarity, its synthesis and physiological expressions.

- To define and describe chakras and their relationship with the nervous and endocrine systems.

\section{CLINICAL BIOENERGETICS - (30 hours)}

\section{General objective}

- To define the concept of health according to Bioenergetics Medicine and the several ways to achieve it.

\section{Specific objectives}

- To explain the concept of health and illness from the point of view of tBioenergetics Medicine.

- To classify the bioenergetic therapies keeping in mind the Bioenergetic Medicine point of view.

- To describe the methods used in those bioenergetic therapies illustrating them with practical examples.

\subsubsection{Option B}

\section{PHYSICS IN MEDICINE AND BIOLOGY - (45 hours)}

\section{General objectives}

- To interpret the physical fundamental concepts that contribute to an understanding and a more precise and efficient use of the techniques of Bioenergetics Medicine.

- To define the main magnitudes that characterize the several types of movement of matter and the laws that are related.

\section{Specific objectives}

- To integrate the language of investigators, technologists and other professionals of the medicbiological universe.

- To identify the physical fundamental concepts about energy, the different fields, and the several forms of movement.

- To define the diverse magnitudes of the field in order to characterize the energy and the several forms of movement as well as to know the fundamental laws that are related.

- To characterize the several forms of movement as well as to know the fundamental laws of physics.

\section{OPTICS- (30 hours)}

\section{General objective}

- To characterize the bases of ondulatories and corpuscular phenomena of light, and the several devices which are present in optic equipment.

\section{Specific objectives}

- To describe the processes of formation of images with mirrors and lenses.

- To explain the functions of the optic fiber.

- To describe the phenomenon of interference, diffraction and polarization of light as well as the bases of the operation of photodetectors and sources of light. 


\section{APPLIED INFORMATION THEORY- (30 hours)}

\section{General objectives}

- To explain the bases of the emission, transmission and reception of signals and information.

Specifics objectives

- To define the different magnitudes related to the transmission of signals.

- To define the concept of Entropy .

- To describe the types of equipment used in signal detection and electrical measurement.

\subsection{Specialized Formation Phase}

\section{BIOMÉDICAL OPTICS - (25 hours)}

\section{General objective}

- To know the foundations of instruments and optic techniques that are used in Life Sciences.

- To explain the biological and physiological bases of interaction processes of light on living beings (plants, animals and humans).

\section{Specific objectives}

- To describe the optic techniques in question, contributing to the solution of problems on behalf of these investigations.

- To characterize the equipping as well as norms that should govern its use.

- To apply these bases in the development of state-of-the-art investigation.

\section{OPTICAL BIOENERGETICS- (45 hours)}

\section{General objective}

- To explain the current tendencies of the use of light on diagnosis and treatment according to Bioenergetics Medicine.

\section{Specific objectives}

- To explain the luminous emissions and the exchanges of photons on living beings as well as in the microscopic and macroscopic level.

- To describe the effects of light on living beings.

- To demonstrate the possibilities of human beings to perceive the subtle energy and develop abilities for this.

\section{LASER IN MEDICINE- (45 hours)}

\section{General objective}

- To describe the physical bases of laser operation, its classification, and description as well as general technical aspects of the laser equipment and more frequent technological solutions.

Specific objectives

- To explain the physical bases of laser functioning.

- To describe the most important technical aspects of the design of laser types.

- To know security norms for the adequate use laser equipment according to different types.

\section{EVALUATION SYSTEM}

The evaluation of the several modules will be carried out in several modalities: exams, tasks, course projects, and practical activities in laboratories and hospitals. 


\section{REFERENCES}

1. Master and Doctorate in Optics Program. Center of Scientific Investigation and Higher Education of Ensenada (CISESE). Ensenada, Mexico, 1993.

2. Master in Optics Program. Department of Physics, ISPJAE, Havana, Cuba, 1995.

3. Master on Physics Science Program. Faculty of Physics, University of Havana, Cuba, 1994.

4. Carvajal J. Un Arte de Curar. Editorial Norma, Colombia, 1997.

5. Carvajal J. Curso de Bioenergética. Notes of Professor. Medellin. Colombia. 